\title{
Correction to: Enhancement of sensitivity and quantification quality in the LC-MS/MS measurement of large biomolecules with sum of MRM (SMRM)
}

\author{
Liang Tang $^{1} \cdot$ Robert R. Swezey ${ }^{1} \cdot$ Carol E. Green $^{1} \cdot$ Jon C. Mirsalis ${ }^{1}$
}

Received: 2 February 2022 / Accepted: 2 February 2022/Published online: 8 February 2022

(c) Springer-Verlag GmbH Germany, part of Springer Nature 2022

Correction to: Analytical and Bioanalytical Chemistry

https://doi.org/10.1007/s00216-021-03829-z

The authors would like to call the reader's attention to the fact that, unfortunately, the references in the references list of this article were unnumbered. The original article has been corrected.

Publisher's note Springer Nature remains neutral with regard to jurisdictional claims in published maps and institutional affiliations.

The original article can be found online at https://doi.org/10.1007/ s00216-021-03829-z.

Liang Tang

Liang.Tang@sri.com

1 SRI Biosciences, SRI International, 333 Ravenswood

Avenue, Menlo Park, CA 94025, USA 